\title{
Primary nongestational choriocarcinoma of the ovary
}

\author{
G.C. Raju, J. Woo, D. Marchack and V. Naraynsingh \\ Departments of Pathology and Obstetrics and Gynecology, Port-Of-Spain General Hospital, Trinidad, West Indies.
}

\begin{abstract}
Summary: Primary choriocarcinoma of the ovary arising, presumably, from a germ cell is extremely rare. The patient, a 16 year old girl who presented with dysuria and frequency of micturition developed fatal haemoperitoneum due to rupture of a pure primary nongestational ovarian choriocarcinoma.
\end{abstract}

\section{Introduction}

Primary choriocarcinoma of the ovary is a rare condition (Novak \& Woodruff, 1974). It may either be gestational following ovarian pregnancy or nongestational arising in a teratoma. Primary nongestational ovarian choriocarcinomas usually occur in an admixture with a teratocarcinoma, dysgerminoma or undifferentiated carcinoma. Pure primary nongestational choriocarcinoma of the ovary is exceedingly rare and we record such a case.

\section{Case report}

A 16 year old girl, gravida 0, was admitted to the hospital with a history of dysuria and frequency of micturition of one week duration and a low grade pyrexia for a month.

Her temperature was $37^{\circ} \mathrm{C}$, pulse rate 130 beats/ min, and blood pressure $110 / 60 \mathrm{~mm} \mathrm{Hg}$. She was anaemic. The abdomen was soft with bilateral loin and suprapubic tenderness. There was no free fluid in the peritoneal cavity. The external genitalia were normal and she was still a virgin.

Investigations revealed a haemoglobin $5.5 \mathrm{~g} / \mathrm{dl}$. Blood biochemistry and complete urinalysis were normal.

The patient had a cardiac arrest while in the radiology department and all resuscitating measures were unsuccessful.

Postmortem examination showed $4200 \mathrm{ml}$ of blood with clots in the peritoneal cavity. A necrotic ruptured tumour, $18 \mathrm{~cm}$ in size, was seen in the right ovary. There were multiple nodular tumour deposits at both lung bases. The uterus, fallopian tubes and the left ovary were normal macroscopically and microscopically. Multiple histological sections of the tumour

Correspondence: G.C.. Raju, M.R.C.Path. 15 Wainwright Street, St Clair, Port-Of-Spain, Trinidad, W.I.

Accepted: 27 February 1985 mass of the right ovary as well as the lung deposits showed only elements of choriocarcinoma and there was no evidence of other germ cell tumour elements (Figure 1).

\section{Discussion}

Primary choriocarcinoma of the ovary is very rare and may be gestational or nongestational. Most nongestational choriocarcinomas in the ovary occur in admixture with teratoma, endodermal sinus tumour, embryonal carcinoma or dysgerminoma (Gerbie et al., 1975). Pure primary ovarian choriocarcinoma derived from germ cells are extremely rare (Hay \& Stewart, 1969; Panayaton et al., 1971). In a review of the literature on both mixed and pure primary choriocarcinomas of the ovary, the age range of the patients was 7 months to $35 \mathrm{y}$ with a mean of about 13 y (Fox \& Langley, 1976).

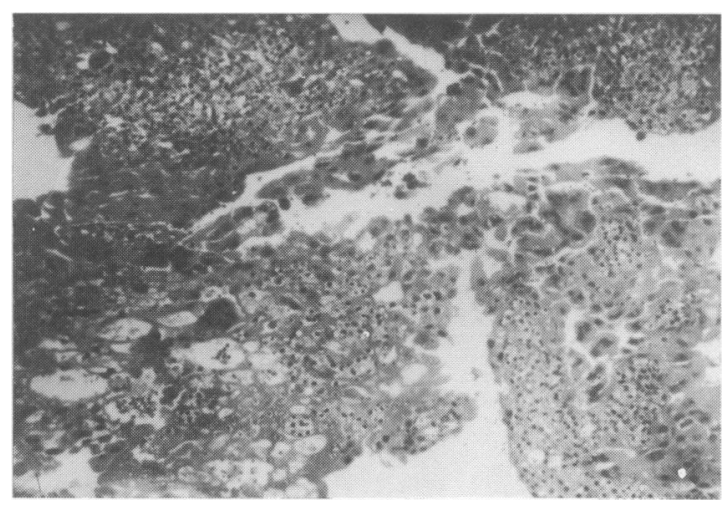

Figure 1 Section from ovarian tumour showing only malignant cyto and syncytiotrophoblasts without villi. (H. \& E. $\times 200)$.

(C) The Fellowship of Postgraduate Medicine, 1985 
Gestational choriocarcinoma arising in the uterus usually presents with the appearance or continuance of bleeding after evacuation of a vesicular mole, or during or after full term pregnancy, or after miscarriage (Novak \& Woodruff, 1974). The symptoms and signs of nongestational choriocarcinoma of the ovary frequently include lower abdominal or iliac fossa pain, a palpable abdomino-pelvic mass, ascitis and complaints due to distant metastasis (Hreshchyshyn, 1982). These findings were similar to ovarian malignancy in general with the addition of symptoms related to suspected pregnancy (Gerbie et al., 1975; Sengupta \& Hamilton, 1981; Vogler et al., 1981). Positive pregnancy test and elevated titres of human chorionic gonadotrophin are constant findings in choriocarcinoma, but these may rarely occur in other malignant ovarian tumours (Scully, 1982). To be unequivocally derived from germ cells, ovarian choriocarcinoma should be diagnosed in a nonpreg-

\section{References}

FOX, H. \& LANGLEY, F.A. (1976). Tumours of the Ovary. Heinemann: London.

GERBIE, M.V., BEEVER, J.I. \& JAMINI, H. (1975). Primary choriocarcinoma of the ovary. Obstetrics and Gynecology. 46, 720 .

HAY, D.M. \& STEWART, D.B. (1969). Primary ovarian choriocarcinoma. Journal of Obstetrics and Gynaecology of the British Commonwealth, 76, 941.

HRESHCHYSHYN, M.M. (1982). Trophoblastic neoplasia. In Cancer Medicine, 2nd edition, p. 2022. Holland, J.F. \& Frei III, E. (eds.). Lea and Febiger: Philadelphia.

MAGRATH, I.T., GOLDING, P.R. \& BAGSHAWE, K.D. (1971). Medical presentations of choriocarcinoma. British Medical Journal, 2, 633.

NOVAK, E.R. \& WOODRUFF, J.D. (1974). In Gynecologic and Obstetric Pathology, 7th edition, p. 623. W.B. Saunders Co.: Philadelphia.

PANAYATON, P.P., VRETTOS, A.S., PAPATHEODOROV, B. \& PARSONS, G.H. (1971). Primary nongestational choriocarcinoma of the ovary. International Surgery, 55, 137. nant women or prepubertal girl.

Our patient presented with urinary symptoms probably due to the tumour pressure on bladder neck or urethra and developed fatal haemoperitoneum due to rupture of the tumour. Overt bleeding from metastases may occur in the gastrointestinal tract, kidney, brain or lung and pulmonary manifestations are the most frequent presenting symptoms of choriocarcinoma (Magrath et al., 1971). Bilateral spontaneous pneumothorax as the presenting symptom of nongestational choriocarcinoma of the ovary has been also reported (Stevens et al., 1979).

Modern treatment of nongestational choriocarcinoma of the ovary depends on surgical excision and a choice of combination chemotherapy based upon thorough histological evaluation of all the elements present (Wider et al., 1969; Gerbie et al., 1975). Serial human chorionic gonadotrophin estimations are of value in monitoring treatment.

SCULLY, R.E. (1982). Choriocarcinoma. In Tumours of the ovary and maldeveloped gonads. Atlas of Tumour Pathology, 2nd series, p. 243. AFIP: Washington D.C.

SENGUPTA, S.K. \& HAMILTON, D.R. (1981). Primary nongestational choriocarcinoma of the ovary. Australian and 8 New Zealand Journal of Obstetrics and Gynecology, 21, 252.

STEVENS, R.P., PIERCE, T.H., DOOLEY, P.C. \& PARSONS, G.H. (1979). Bilateral spontaneous pneumothorax in nongestational choriocarcinoma. Canadian Medical Association Journal, 120, 830.

VOGLER, C., SCHMIDT, W.A. \& EDWARDS, G.L. (1981). Primary ovarian nongestational choriocarcinoma. Report of a case in a young woman of child bearing age. Diagnostic Gynecology and Obstetrics, 3, 331.

WIDER, J.A., MARSHALL, J.R., BARDIN, C.W., LIPSETT, M.B. \& ROSS, G.T. (1969). Sustained remission after chemotherapy for primary ovarian cancers containing choriocarcinoma. New England Journal of Medicine, 280, 1439. 